\title{
CUIDADO DE ENFERMAGEM À CRIANÇA COM DOENÇA ONCOLÓGICA AVANÇADA: UM OLHAR FENOMENOLÓGICO
}

Cintia Flôres Mutti ${ }^{1}$, Stela Maris de Mello Padoin², Cristiane Cardoso de Paula ${ }^{2}$

\begin{abstract}
RESUMO: Trata-se de um projeto de pesquisa de mestrado com abordagem qualitativa, de natureza fenomenológica e pautada no referencial teórico-filosófico-metodológico de Martin Heidegger,a ser desenvolvido entre 2010 e 2011, com o objetivo de compreender o significado, para a equipe de enfermagem, sobre o cuidar de criança com doença oncológica avançada cuja enfermidade não responde mais aos tratamentos curativos. A etapa de campo da pesquisa será desenvolvida em um hospital de ensino do Sul do Brasil, em três unidades: centro de tratamento à criança e ao adolescente com câncer, unidade de terapia intensiva pediátrica e ambulatório de quimioterapia. Os participantes serão as equipes de enfermagem das três unidades. A produção dos dados será realizada por meio de entrevista fenomenológica; para a análise serão desenvolvidos os dois momentos metódicos de Martin Heidegger: compreensão vaga e mediana e a hermenêutica.

PALAVRAS-CHAVE:Enfermagem; Saúde da criança; Neoplasias; Cuidados paliativos.

\section{NURSING CARE FOR THE CHILD WITH ADVANCED ONCOLOGICAL ILLNESS: A PHENOMENOLOGICAL VIEW}

ABSTRACT: A Master's course research project with a qualitative approach, a phenomenological character, and methodologized in the theoretical-philosophical-methodological approach of Martin Heidegger, to be developed between 2010 and 2011, with the objective of understanding the meaning, for the nursing team, about caring for a child with an advanced oncological illness that no longer responds to healing treatments. The field stage will be developed in a teaching hospital in South Brazil, in three units; a center of treatment for children and adolescents with cancer, a pediatric intensive therapy unit, and a mobile chemotherapy unit. The participants will be nursing teams from the three units. Data production will be carried out through phenomenological interviews: for analysis, the two Heideggerian methodical moments will be developed - vague and median comprehension and the hermeneutic.

KEYWORDS: Nursing; Children's health; Neoplasias; Palliative care.

\section{CUIDADO DE ENFERMERÍA AL NINÕ CON ENFERMEDAD ONCOLÓGICA AVANZADA: UNA MIRADA FENOMENOLÓGICA}

RESUMEN: Es un proyecto de investigación de mestrado con abordaje cualitativo, de naturaleza fenomenológica y pautada en referencial teórico-filosófico-metodológico de Martin Heidegger, a ser desarrollado entre 2010 y 2011, con el objetivo de comprender el significado, para el equipo de enfermería, acerca del cuidar del niño con enfermedad oncológica avanzada cuya enfermedad no responde más a los tratamientos curativos. La etapa de campo de la investigación será desarrollada en un hospital de enseñanza del Sur de Brasil, en tres unidades: centro de tratamiento al niño y al adolescente con cáncer, unidad de terapia intensiva pediátrica y ambulatorio de quimioterapía. Los participantes serán los equipos de enfermería de las tres unidades. La producción de los datos será realizada por medio de entrevista fenomenológica; para el análisis serán desarrollados los dos momentos metódicos de Martin Heidegger: comprensión vaga y mediana y la hermenéutica. PALABRAS CLAVE: Enfermería; Salud del niño; Neoplasias; Cuidados paliativos.

${ }^{1}$ Enfermeira. Especialista em Oncologia. Mestranda no Programa de Pós-Graduação em Enfermagem da Universidade Federal de Santa Maria - PPGEnf UFSM. Bolsista CAPES. Membro do Grupo de Pesquisa Cuidado à Saúde das Pessoas, Famílias e Sociedade.

${ }^{2}$ Enfermeira. Doutora em Enfermagem. Professora do Departamento de Enfermagem e do PPGenf UFSM. Membro do Grupo de Pesquisa Cuidado à Saúde das Pessoas, Famílias e Sociedade.

Autor correspondente:

Cintia Flôres Mutti

Universidade Federal de Santa Maria

Endereço: Av. Borges de Medeiros, 1988 - 97010-080 - Santa Maria-RS-Brasil.

E-mail: cfmutti@hotmail.com

Recebido: $10 / 01 / 11$

Aprovado: 05/04/11 


\section{INTRODUÇÃO}

A sobrevida de crianças com câncer tem aumentado consideravelmente com o suporte de centros especializados para o tratamento; a cura ultrapassa $70 \%$ dos $\operatorname{casos}^{(1)}$. O diagnóstico de neoplasia na infância suscita mudança repentina e drástica na rotina de vida, perpassando o tratamento até o desfecho imprevisível de cura ou a impossibilidade desta, o que causa sofrimento à criança, família e profissionais ${ }^{(2)}$.

Quando a doença avança e a terapêutica curativa não é viável, a criança com neoplasia necessita, na maioria das vezes, permanecer em unidades de internação ou de tratamento intensivo. O cuidado de enfermagem, neste contexto, envolve o controle da dor, da ansiedade e da depressão, além do compartilhar as decisões do cuidar com a criança e sua família( ${ }^{(3)}$.

A produção científica na temática aponta uma natureza clínico-epidemiológica e sócio-cultural, e uma tendência curativa ${ }^{(4)}$. Contempla-se a necessidade de dar visibilidade a esse grupo com estudos que envolvam as próprias crianças, seus familiares e os profissionais de saúde, não só na dimensão objetiva como também nas dimensões subjetiva e existencial.

Assim, tem-se a questão: como se sentem os profissionais de enfermagem que vivenciam o cuidado à criança com doença oncológica avançada? $\mathrm{O}$ estudo tem como objetivo compreender o significado, para a equipe de enfermagem, de cuidar de criança com doença oncológica avançada cuja enfermidade não responde mais aos tratamentos curativos.

\section{METODOLOGIA}

Trata-se de um estudo qualitativo com abordagem fenomenológica e pautada no referencial teórico-filosófico-metodológico de Martin Heidegger ${ }^{(5)}$. Entende-se que é necessário e oportuno compreender os sentimentos, as emoções e os significados que o ser humano confere às situações experienciadas e vivenciadas ${ }^{(6)}$.

A etapa de campo da pesquisa será desenvolvida em um hospital de ensino do Sul do Brasil, em três unidades: centro de tratamento à criança e ao adolescente com câncer, unidade de terapia intensiva pediátrica e ambulatório de quimioterapia. Os participantes serão os profissionais das equipes de enfermagem das unidades que conforme os critérios de inclusão: 1) desenvolvem ações de cuidado às crianças com doença oncológica avançada cuja enfermidade não responde mais aos tratamentos curativos e 2) integram o quadro de pessoal (enfermeiro, técnico ou auxiliar de enfermagem) de uma das três unidades supracitadas. São critérios de exclusão: estar afastado ou em licença das atividades profissionais. Concomitante à etapa de campo será desenvolvida a etapa de análise. A etapa de campo chegará ao fim quando os significados expressos nos depoimentos anunciarem o desvelamento do sentido ${ }^{(7)}$.

Para a produção dos dados será realizada a entrevista fenomenológica, com a pergunta orientadora: Conte-me como é para você cuidar de crianças com doença oncológica avançada?

A análise, pelo método heideggeriano, será desenvolvida em dois momentos metodológicos: análise compreensiva e análise interpretativa. O período previsto para o estudo é de 2010 a 2011. Serão respeitados os preceitos éticos dispostos na Resolução n.196/96; o projeto de pesquisa foi aprovado pelo Comitê de Ética da Universidade Federal de Santa Maria, Rio Grande do Sul, sob protocolo CAAE 0284.0.243.000-10.

\section{REFERÊNCIAS}

1. Ministério da Saúde (BR). Diagnóstico precoce do câncer na criança e no adolescente. Rio de Janeiro: INCA; 2009.

2. Monteiro CFS, Veloso LUP, Sousa PCB, Morais SCR. A vivência familiar diante do adoecimento e tratamento de crianças e adolescentes com leucemia linfóide aguda. Cogitare Enferm. 2008;13(4):484-9.

3. Santos MCL, Pagliuca LMF, Fernandes AFC. Cuidados paliativos ao portador de câncer: reflexões sob o olhar de Peterson e Zderad. Rev Latino-Am Enfermagem. 2007;15(2):350-4.

4. Mutti CF, Paula CC, Souto MD. Assistência à saúde da criança com câncer na produção científica brasileira. Rev Bras Cancerol. 2010;56(1):71-83.

5. Ser e tempo. Trad. de Márcia Sá Cavalcante Schuback. $14^{\mathrm{a}}$ ed. Petrópolis: Vozes; 2005. Parte I.

6. Padoin SMM, Souza IEO. A compreensão do temor como modo de disposição da mulher com HIV/AIDS diante da (im)possibilidade de amamentar. Texto \& Contexto Enferm. 2008;17(3):510-8.

7. Boemer MR. A condução de estudos segundo a metodologia de investigação fenomenológica. Rev. Latino-Am Enfermagem. 1994;2(1):83-94. 